\title{
Aspek Kepemimpinan Dan Kompetensi Aparatur Birokrasi Serta Dampaknya Terhadap Peningkatan Kinerja
}

\author{
Andi Riyanto \\ Universitas Bina Sarana Informatika, andi.iio@bsi.ac.id
}

\begin{abstract}
ABSTRAK
Sumber daya manusia mempunyai peran utama dalam setiap kegiatan organisasi. Walaupun di dukung dengan sarana dan prasarana serta sumber dana yang berlebihan, tetapi tanpa dukungan sumber daya manusia yang andal, kegiatan di organisasi publik khususnya pada Dinas Pekerjaan Umum, Penataan Ruang, Perumahan, Kawasan Pemukiman \& Pertanahan (PUPRPKPP) Kota Sukabumi tidak akan terselesaikan dengan baik. Hal ini menunjukkan bahwa sumber daya manusia merupakan kunci pokok yang harus diperhatikan dengan segala kebutuhannya. Sebagai kunci pokok, sumber daya manusia akan menentukan keberhasilan pelaksanaan kegiatan Dinas PUPRPKPP Kota Sukabumi. Penelitian dilakukan di Dinas PUPRPKPP Kota Sukabumi. Tujuan penelitian ini adalah untuk mengetahui sejauh mana dampak kepemimpinan dan kompetensi aparatur birokrasi terhadap peningkatan kinerja. Metode penelitian yang digunakan adalah metode survei. Responden penelitian adalah aparatur di Dinas PUPRPKPP Kota Sukabumi sebanyak 518 orang sebagai populasi, selanjutnya sampel diambil menggunakan metode purposive sampling sebanyak 47 pegawai yaitu aparatur di Dinas PUPRPKPP Bidang Bina Tata Bangunan. Teknik pengumpulan data menggunakan instrumen yang berbentuk angket, untuk variabel kepemimpinan, kompetensi dan kinerja. Instrumen di analisis dengan menggunakan uji reliabilitas, uji validitas dan uji normalitas. Data penelitian dianalisis menggunakan teknik korelasi dan persamaan regresi. Hasil penelitian menunjukkan bahwa terdapat dampak yang positif antara kepemimpinan dan kompetensi secara simultan terhadap kinerja.
\end{abstract}

Kata Kunci : Kepemimpinan, Kompetensi, Aparatur Birokrasi, Kinerja.

\begin{abstract}
Human resources have a major role in every organization's activities. Although supported by facilities and infrastructure as well as excessive funding sources, but without the support of reliable human resources, activities in public organizations, especially at the Public Works Office, Spatial Planning, Housing, Settlement \& Land Areas (PUPRPKPP) Sukabumi City will not be completed with well. This shows that human resources are the main key that must be considered with all their needs. As a key point, human resources will determine the successful implementation of Sukabumi City PUPRPKPP activities. The research was conducted at the PUPRPKPP Sukabumi City Office. The purpose of this study was to determine the extent of the impact of bureaucratic apparatus leadership and competencies on improving performance. The research method used was a survey method. The research respondents were apparatus in the PUPRPKPP Office of Sukabumi City with a total of 518 people as a population, then the sample was taken using a purposive sampling method of 47 employees, namely apparatus in the PUPRPKPP Office of Building Management as many as 47 employees. Data collection techniques using instruments in the form of a questionnaire, for the variables of leadership, competence and performance. The instruments were analyzed using the reliability test, validity test and normality test. Research data were analyzed using correlation techniques and regression
\end{abstract}

ISSN: 2355-0295, e-ISSN: 2549-8932 
equations. The results showed that there was a positive impact between leadership and competency simultaneously on performance.

Keywords: Leadership, Competencies, Bureaucracy Apparatus, Performance.

Naskah diterima : 21 Agustus 2019, direvisi: 26 Agustus 2019, diterbitkan: 16 September 2019 


\section{PENDAHULUAN}

Era perubahan dan kompleksitas yang cepat, termasuk kebutuhan untuk mengembangkan bakat manajerial semakin jelas (Day, Harrison, \& Halpin, 2012). Dasawarsa ini, organisasi publik menyaksikan dua reformasi utama selama dekade terakhir. Pertama, manajemen publik bertujuan agar sektor publik berevolusi dari organisasi birokrasi menuju yang lebih akuntabel, efisien dan kurang terpusat (Walker, Boyne, \& Brewer, 2010). Kedua, tata kelola organisasi publik baru menghasilkan organisasi publik dengan yang lebih kuat penekanannya pada kompetisi dan tanggung jawab terhadap pengguna layanan publik tersebut (Osborne, 2006). Begitupun di Indonesia, tuntutan pasca reformasi yang digulirkan menciptakan perubahan yang sangat mendasar terhadap tata kelola organisasi publik, dalam hal ini pemerintahan dan dimensi kehidupan birokrasi. Dalam proses pelaksanaan pemerintahan daerah sesuai dengan amanat pembukaan Undang-undang Dasar 1945 tercermin dalam bentuk keberadaan pemerintahan ditingkat lokal. Dengan berlakunya undang-undang pelaksanaan pemerintahan daerah yaitu Undang-Undang No 22 Tahun 1999 tentang Pemerintahan Daerah yang saat ini telah diperbaharui dengan Undang-Undang No 32 Tahun 2004 memberikan suatu fenomena baru dan angin segar bagi pemerintah daerah dalam menyelenggarakan fungsi pemerintahan. Terjadinya transisi pemerintahan yang berkali-kali, menyebabkan terjadinya perubahan sistem dan struktur kepemerintahan baik di pusat maupun di daerah. Untuk menghadapi perubahan tersebut Pemerintah Kota Sukabumi berkewajiban meningkatkan kemampuan aparatur pemerintahannya di berbagai bidang. Antara lain peningkatan faktorfaktor kemampuan sumber daya manusianya seperti kepemimpinan dan peningkatan kompetensi dari Aparatur Sipil Negara itu sendiri. Hal ini sesuai dengan tujuan capaian sasaran pembangunan nasional, dimana dasar yang terpenting adalah pengelolaan dan pengembangan
Sumber Daya Manusia (SDM) Aparatur Sipil Negara (ASN) yang sesuai dengan kebutuhan pembangunan (Brodjonegoro, 2018). Pengelolaan dan pengembangan SDM sejalan dengan perkembangan masyarakat saat ini, yang mana tuntutan akan kualitas pelayanan publik dari ASN harus meningkat. Birokrasi yang diharapkan mampu menjadi motivator dan sekaligus menjadi katalisator dari bergulirnya pembangunan, tidak hanya mampu menjalankan perannya sebagai birokrasi modern dan tidak hanya mengedepankan kemampuan menyelenggarakan tugas dan fungsi organisasi saja tetapi juga dituntut harus mampu merespons aspirasi publik ke dalam kegiatan dan program organisasi dan mampu melahirkan inovasi baru yang bertujuan untuk mempermudah kinerja organisasi dan sebagai bagian dari wujud aparat yang profesional (Riyanto, 2014).

Masyarakat bukan hanya mempersoalkan terpenuhinya atau tidaknya kebutuhan akan jasa dan layanan publik, akan tetapi mempertanyakan mutu dan kualitas layanan publik yang mereka terima dari pemerintah. Untuk memenuhi tuntutan pelayanan dengan kualitas yang ditentukan oleh masyarakat sebagai pelanggan, maka pemerintah dituntut untuk mampu meningkatkan kualitas pelayanan kepada masyarakat. Namun dalam kenyataannya aparat pemerintah umumnya belum sadar mengenai posisinya sebagai pelayan masyarakat dan juga filosofi pelayanan itu sendiri. Ini terlihat dari kondisi riil kualitas ASN yang masih belum optimal dalam mendukung kinerja pemerintah. Dari 4,5 juta orang jumlah ASN di Indonesia, 38 persen ASN hanya memiliki kemampuan administrasi umum atau juru ketik. Sementara itu, 37 persen adalah guru, dan sisanya dari sektor profesional dan sebagainya (Abnur, 2018). Kepemimpinan dalam organisasi telah dipahami dan dianggap sebagai suatu hal yang sangat berperan dan mempengaruhi seluruh aspek organisasional baik secara langsung maupun tidak langsung. Artinya keberadaan dan tindakan para pemimpin menentukan keberhasilan kegiatan- 
kegiatan dalam organisasi tersebut. Banyak penelitian juga telah membuktikan bahwa kepemimpinan berpengaruh terhadap perilaku para pegawai, hubungan diantara mereka dan kondisi lingkungan kerja. Pentingnya kepemimpinan ini bahkan diyakini sebagai prime enabler atau faktor utama yang memungkinan fungsi-fungsi organisasi berjalan, dalam excellence business model yang dibuat oleh European Foundation for Quality Management (Storey, 2004). Kepemimpinan harus dijalankan menggunakan gaya kepemimpinan yang tepat, yaitu yang dapat diikuti dan dipatuhi serta memberi motivasi kepada para pengikutnya, dan sesuai dengan kebutuhan organisasi. Hal ini menandakan bahwa posisi atau jabatanjabatan strategis dalam organisasi, harus diisi oleh para pegawai yang benar-benar mampu dan berkomitmen menjalankan kepemimpinannya. Sepenuhnya harus disadari manfaat membangun kapasitas kepemimpinan, organisasi harus berkembang melampaui fokus yang membatasi hanya pada satu kepemimpinan formal, dan pegawai berpotensi besar, yang membuat pengaruhnya terbatas. Sebaliknya, organisasi harus mengidentifikasi cara untuk meningkatkan kapasitas untuk gaya kepemimpinan dan pengaruh kepemimpinan tersebut terhadap pegawai di lingkungan organisasi birokrasi (Scott, Jiang, Wildman, \& Griffith, 2018). Untuk dapat memberikan pelayanan yang berkualitas tersebut banyak hal yang mempengaruhinya diantaranya adalah faktor pemimpin dan kemampuan yang dimiliki pegawai itu sendiri sebagai pemberi layanan. Namun dalam kenyataannya aparat pemerintah umumnya belum sadar mengenai posisinya sebagai pelayan masyarakat dan juga filosofi pelayanan itu sendiri.

Tujuan dari riset ini untuk mengetahui impact kepemimpinan terhadap kinerja aparatur Dinas Pekerjaan Umum, Penataan Ruang, Perumahan, Kawasan Pemukiman \& Pertanahan (PUPRPKPP) Kota Sukabumi, untuk mengetahui dampak kompetensi terhadap kinerja aparatur Dinas PUPRPKPP Kota Sukabumi dan untuk mengetahui dampak kepemimpinan dan kompetensi aparat secara simultan terhadap kinerja aparatur Dinas PUPRPKPP Kota Sukabumi.

\section{KAJIAN LITERATUR \\ Kepemimpinan}

Tinjauan berbagai literatur kepemimpinan mengungkapkan serangkaian teori 'aliran pemikiran' yang berevolusi dari teori "Great Man" dan "Trait" ke kepemimpinan "Transformasional". Sementara teori awal cenderung berfokus pada karakteristik dan perilaku para pemimpin yang sukses, teori kemudian mulai mempertimbangkan peran pengikut dan sifat kontekstual kepemimpinan (Bolden, Gosling, Marturano \& Dennison, 2003). Maka itu kepemimpinan terjadi ketika pemimpin dan pengikut dapat mengembangkan hubungan yang efektif (kemitraan) yang menghasilkan pengaruh tambahan (Uhl-bien, 2006). Hal ini sejalan dengan beberapa teori kepemimpinan yang sudah diakui dan akan terus menarik minat terhadap beberapa faktor teori pendukung kepemimpinan seperti teori neokarismatik, pemrosesan informasi, sifat, dan teori pertukaran antara pemimpin-pengikut (Dinh et al., 2013). Hubungan pemimpinpengikut dalam organisasi dapat meningkatkan kinerja organisasi tersebut, salah satunya dengan memberikan reward kepada bawahan berupa promosi jabatan yang sesuai dengan ketentuan yang berlaku (Junaidi \& Susanti, 2019).

Cara memimpin yang merupakan pola konsisten dari seorang pemimpin digambarkan dalam teori tiga (3) dimensi sebagai berikut :

1. Task Orientation, gaya seorang pemimpin dapat dilihat dari kualitas keinginannya untuk menyelesaikan suatu pekerjaan.

2. Relationship Orientation, tipe pemimpin dapat juga dilihat dari kualitas perhatiannya terhadap hubungan dengan orang lain, baik hubungan dengan atasannya, dengan koleganya yang setingkat dan terutama dengan bawahannya.

3. Effectiveness Orientation, yang menyebabkan seorang pemimpin yang satu berbeda dengan pemimpin yang 
lainnya adalah kemauannya untuk memperoleh produktivitas yang tinggi.

(Nugroho, 2017)

Kolaborasi antara pemimpin dan bawahan dalam menciptakan iklim kerja yang kondusif akan berdampak pada kegiatan operasional institusi itu sendiri yang sesuai dengan prinsip-prinsip pemerintahan yang baik (good governance).

\section{Kompetensi}

(Osei \& Ackah, 2015) mendefinisikan kompetensi sebagai perilaku yang terkait dengan pengetahuan dan keterampilan yang dibutuhkan untuk melaksanakan misi tertentu secara efektif, dan perilaku itu dapat menjadi seperangkat sifat pribadi atau seperangkat standar dan termasuk sifat-sifat kinerja.

Secara teori, kompetensi pegawai dianggap sebagai pendorong utama kinerja organisasi (Čižiuniene, Vaičiute, \& Batarliene, 2016). Sejumlah besar studi telah menyelidiki peran berbagai kompetensi karyawan, termasuk kompetensi teknologi, pemasaran dan integratif, dalam meningkatkan kinerja organisasi (Yup Chung, 2000). Contohnya, keahlian komputer dan bahasa, perasaan dan etika, kerjasama tim dan kepemimpinan, pengetahuan dan keterampilan (Lertwannawit, Serirat, \& Pholpantin, 2009) semua terbukti menjadi penentu kinerja organisasi. Organisasi tidak akan dapat mencapai tujuan mereka tanpa kehadiran karyawan yang kompeten, terutama di bawah lingkungan kerja saat ini (Čižiuniene et al., 2016).

Selain itu, seorang pegawai dalam hal ini aparatur birokrasi harus memiliki kategori skill berikut agar efektif dalam mengelola dan mengatur organisasinya,; technical, human dan conceptual. Technical skill adalah kemampuan berorientasi detail yang diperlukan untuk aparatur tingkat pemula. Human skill adalah itu kemampuan interpersonal yang diperlukan untuk dapat mengelola sekelompok orang atau yang dapat berinteraksi dalam one-on-one format. Membangun tim dan komunikasi adalah contoh dari human skill. Conceptual skill adalah kemampuan aparatur dalam perencanaan dan visioner (mampu melihat ke depan) (Katz, 1974; Weber, Finley, Crawford, \& Rivera, 2009).
Kinerja

Kinerja dan keberhasilan organisasi mana pun tergantung pada pegawai yang terampil dan bagaimana caranya organisasi dapat bertindak efisien dengan memanfaatkan sumber daya yang ada dan memanfaatkannya secara efektif. Kinerja pada level unit inilah sering dianggap sebagai barometer kesuksesan daripada kinerja individu (Pugh \& Dietz, 2008).

Kinerja adalah istilah yang digunakan dalam kehidupan sehari-hari yang menggambarkan perkembangan perjalanan suatu organisasi beserta hasilnya (Brudan, 2010). Dengan kata lain, fungsi kinerja adalah untuk memastikan bahwa kegiatan yang telah dicapai oleh tujuan organisasi secara konsisten dengan cara yang efektif dan efisien sehingga suatu organisasi, departemen, pegawai, atau proses dapat fokus untuk menghasilkan produk atau layanan, dan juga di bidang lainnya.

Pimpinan organisasi publik yang efektif akan memanfaatkan sumber daya organisasinya sedemikian rupa, sehingga berdampak terhadap kinerja yang baik serta kepuasan bagi pegawai yang ikut serta dalam melaksanakan pekerjaan dalam organisasi publik. Terdapat dua kriteria yang berhubungan dengan kinerja organisasi, yaitu efektivitas dan efisiensi (Schermerhorn, 1996) sebagaimana gambar berikut :

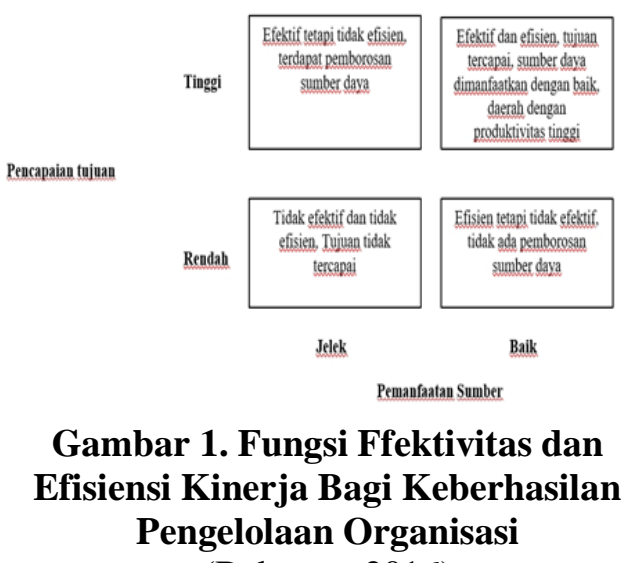

(Baharun, 2016)

Terdapat dua kategori dasar atribut: yang bersifat internal atau yang berhubungan dengan karakteristik personal, dengan yang bersifat ekternal atau yang berhubungan dengan lingkungan personal. Seperti, perilaku (kinerja) yang ada relasinya hingga 
ke faktor spesifik seperti kemampuan, upaya, kesulitan tugas, atau nasib baik. Kemampuan dan upaya adalah penyebabpenyebab yang bersifat internal bagi ekternal. Demikian juga dengan sejumlah faktor lain juga dapat juga mempengaruhi kinerja, seperti perilaku, sikap dan tindakan-tindakan partner kerja, seperti bawahan, ataupun pimpinan, kendala sumber daya dan kondisi ekonomi (Timpe, 2002).

\section{METODE PENELITIAN \\ Variabel Penelitian}

Penelitian dilakukan dalam upaya menemukan jawaban atas permasalahan yang telah dirumuskan dengan menggunakan metoda campuran antara metoda kualitatif dan kuantitatif, walaupun demikian metoda kuantitatif memiliki bobot yang lebih banyak karena perolehan data dilengkapi dengan skor sehingga merupakan data yang bersifat kuantitatif yang memiliki parameter, sedangkan kualitatif menggunakan metoda deskriptif. Relasi antar variabel dapat dilihat dalam gambar berikut ;

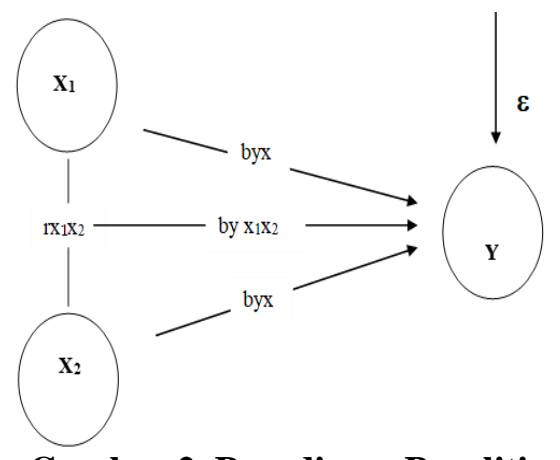

Gambar 2. Paradigma Penelitian

Keterangan :

$\mathrm{X}_{1}=$ variabel bebas pertama, yaitu kepemimpinan

$\mathrm{X}_{2}=$ variabel bebas kedua, yaitu kompetensi aparatur birokrasi

$\mathrm{Y}=$ variabel terikat yaitu kinerja

byx $_{1}=$ menunjukan besarnya dampak $\mathrm{x}_{1}$ terhadap $\mathrm{y}$

byx $_{2}=$ menunjukan besarnya dampak $\mathrm{x}_{2}$ terhadap $\mathrm{y}$

byx $_{1} x_{2}=$ menunjukan besarnya dampak $\mathrm{x}_{1}$ dan $\mathrm{x}_{2}$ terhadap $\mathrm{y}$ $\mathrm{rx} 1 \mathrm{x} 2=$ relasi korelasional $\mathrm{x} 1$ dengan $\mathrm{x} 2$

$\varepsilon=$ faktor lain yang mempengaruhi $\mathrm{y}$ di luar $\mathrm{x}_{1}$ dan $\mathrm{x}_{2}$ yang tidak diukur

Batasan dari variabel-variabel yang ada beserta indikator-indikator untuk mencapai ke arah itu terlihat pada tabel 1 :

\section{Tabel 1}

Operasional Variabel

\begin{tabular}{|c|c|c|}
\hline Variabel & Dimensi & Indikator \\
\hline \multirow{3}{*}{$\begin{array}{c}\text { Kepemimpi } \\
\text { nan } \\
\text { (X1) }\end{array}$} & $\begin{array}{l}\text { Kepemimpi } \\
\text { nan } \\
\text { berorientasi } \\
\text { tugas }\end{array}$ & $\begin{array}{l}\text { 1. Tugas } \\
\text { 2. Kualitas } \\
\text { 3. } \\
\text { Prosedur/pedo } \\
\text { man. }\end{array}$ \\
\hline & $\begin{array}{c}\text { Kepemimpi } \\
\text { nan } \\
\text { berorientasi } \\
\text { hubungan }\end{array}$ & $\begin{array}{l}\text { 1. Hubungan } \\
\text { kerja } \\
\text { 2. Hubungan } \\
\text { manusiawi } \\
\text { 3. Kompromi }\end{array}$ \\
\hline & $\begin{array}{c}\text { Kepemimpi } \\
\text { nan } \\
\text { berorientasi } \\
\text { efektivitas }\end{array}$ & $\begin{array}{l}\text { 1. Pencapaian } \\
\text { 2. Waktu } \\
\text { pencapaian } \\
\text { 3. Target }\end{array}$ \\
\hline \multirow{3}{*}{$\begin{array}{c}\text { Kompetensi } \\
\text { Aparatur } \\
\text { Birokrasi } \\
\text { (X2) }\end{array}$} & $\begin{array}{c}\text { Technikal } \\
\text { Skill } \\
\text { (kemampua } \\
\text { n teknis) }\end{array}$ & $\begin{array}{l}1 . \\
\text { Kemampuan } \\
\text { melaksanakan } \\
\text { Peraturan atau } \\
\text { prosedur } \\
2 . \\
\text { Keterampilan } \\
\text { bekerja }\end{array}$ \\
\hline & $\begin{array}{c}\text { Human } \\
\text { Skill } \\
\text { (kemampua } \\
\mathrm{n} \\
\text { hubungan } \\
\text { manusia) }\end{array}$ & $\begin{array}{l}1 . \\
\text { Kemampuan } \\
\text { memimpin } \\
2 . \\
\text { Kemampuan } \\
\text { beradaptasi }\end{array}$ \\
\hline & $\begin{array}{c}\text { Konseptual } \\
\text { Skill } \\
\text { (kemampua } \\
\text { n Konsep) }\end{array}$ & $\begin{array}{l}1 . \\
\text { Perencanaan } \\
\text { kegiatan } \\
2 . \\
\text { Pengambilan } \\
\text { keputusan }\end{array}$ \\
\hline \multirow{2}{*}{$\begin{array}{l}\text { Kinerja } \\
\text { Aparat } \\
\text { (Y) }\end{array}$} & Efektifitas & $\begin{array}{l}\text { 1. Pencapaian } \\
\text { tujuan } \\
2 . \\
\text { Penyelesaian } \\
\text { kerja }\end{array}$ \\
\hline & Efisiensi & $\begin{array}{l}\text { 1. Penggunaan } \\
\text { sumber daya } \\
\text { 2. Mengurangi } \\
\text { pemborosan }\end{array}$ \\
\hline
\end{tabular}




\section{Metode Pengumpulan Data}

Teknik pengumpulan data yang digunakan adalah dengan angket yaitu memberikan daftar pertanyaan untuk diisi oleh responden yang menjadi sampel dalam penelitian. Kuesioner sebagai alat pengumpul data penelitian dibagikan kepada responden yaitu ASN pada Dinas PUPRPKPP Kota Sukabumi dengan jumlah populasi sebanyak 518 orang. Sampel diambil dengan menggunakan purposive sampling, yaitu kriteria sampel yang diinginkan peneliti berdasarkan tujuan penelitian, dari Dinas PUPRPKPP Bidang Bina Tata Bangunan sebanyak 47 orang pegawai.

\section{Uji Instrumen}

Uji instrumen dilakukan untuk menguji apakah instrumen penelitian yang dikembangkan untuk mengukur konsep tertentu (kuesioner) benar-benar mengukur secara tepat variabel yang akan diteliti. Artinya bahwa instrumen dapat mengukur secara aktual konsep yang telah ditetapkan. Uji instrumen menggunakan uji validitas dan reliabilitas. Uji reliabilitas dilakukan untuk melihat stabilitas dan konsistensi hasil pengukuran. Uji reliabilitas menggunakan Cronbach Alpha. Uji validitas adalah untuk mengukur suatu instrumen apakah mencerminkan arti yang sebenarnya dari konsep yang diteliti, atau untuk mengukur apa yang seharusnya diukur.

\section{Uji Normalitas}

Uji normalitas bertujuan untuk menguji apakah dalam model regresi, variabel pengganggu atau residual memiliki distribusi normal. Dalam penelitian ini uji normalitas dilakukan dengan analisis grafik normal PP Plot.

\section{Metode Analisis Data}

Analisis data menggunakan korelasi dan multipel korelasi, yaitu untuk mengetahui kuatnya dampak atau relasi antara variabel terikat dan variabel bebas, dengan menggunakan pearson product moment correlation : $r_{x y}=\frac{n \sum X Y-\left(\sum X\right)\left(\sum Y\right)}{\sqrt{\left\{n \sum X^{2}-\left(\sum X\right)^{2}\right\}\left\{n \sum Y^{2}-\left(\sum Y\right)^{2}\right\}}}$

Pearson Product Moment correlation dilambangkan ( $\mathrm{r}$ ) dengan ketentuan nilai $\mathrm{r}$ tidak lebih dari harga $(-1<\mathrm{r}<+1)$. Apabila nilai $\mathrm{r}=-1$ artinya korelasinya negatif sempurna; $r=0$ artinya tidak ada korelasi dan $r=1$ berarti korelasinya sangat kuat. Arti harga $r$ akan dikonsultasikan dengan tabel interpretasi nilai $r$ sebagai berikut :

\section{Tabel 2}

\section{Interpretasi Koefisien Korelasi Nilai $\mathbf{r}$}

\begin{tabular}{|c|c|}
\hline $\begin{array}{c}\text { Interval } \\
\text { Koefisien }\end{array}$ & Tingkat Hubungan \\
\hline $0,80-1,000$ & Sangat Kuat \\
\hline $0,60-0,799$ & Kuat \\
\hline $0,40-0.599$ & Cukup Kuat \\
\hline $0,20-0,399$ & Rendah \\
\hline $0,00-0,199$ & Sangat Rendah \\
\hline
\end{tabular}

Uji signifikansi berfungsi apabila peneliti ingin mencari makna relasi antara variabel X terhadap Y, maka hasil korelasi Pearson Product Moment diuji dengan uji signifikansi dengan persamaan :

$$
\mathrm{t}_{\text {hitung }}=\frac{\mathrm{r} \sqrt{\mathrm{n}-2}}{\sqrt{1-\mathrm{r}^{2}}}
$$

Dimana :

$\mathrm{t}_{\text {hitung }}=$ Nilai $\mathrm{t}$

$\mathrm{r} \quad=$ Nilai Koefisien korelasi

$\mathrm{n} \quad=$ Jumlah Sampel

Untuk menguji hipotesis lebih dari dua variabel menggunakan uji $\mathrm{F}$ :

$$
F=\frac{R^{2}(N-m-1)}{M\left(1-R^{2}\right)}
$$

Dimana :

$$
\begin{array}{ll}
\mathrm{F} & =\text { Uji F } \\
\mathrm{N} & \text { = Jumlah Sampel } \\
\mathrm{M} & \text { = Jumlah prediktor (4 variabel) } \\
\mathrm{R}^{2} & =\text { Koefisien korelasi yang } \\
& \text { dikuadratkan }
\end{array}
$$

Jika $\mathrm{F}$ hitung lebih besar dari $\mathrm{F}$ tabel pada taraf nyata 5\%, maka hipotesis yang dirumuskan dapat diterima. 
Koefisien Determinasi $\left(\mathrm{r}^{2}\right)$ digunakan untuk mengetahui besarnya pengaruh variabel independen terhadap variabel dependen, Koefisien Determinasi diperoleh dengan cara mengkuadratkan Koefisian Korelasi kemudian dikalikan $100 \%$.

Persamaan regresi digunakan untuk memperkirakan terjadinya suatu kejadian di waktu yang akan datang, persamaannya regresi sebagai berikut :

$$
Y=a+b X_{1}+b X_{2}
$$

Keterangan :

$\mathrm{Y}=$ nilai $\mathrm{Y}$ prediksi

$\mathrm{a}=$ nilai rata-rata $\mathrm{Y}$ prediksi jika $\mathrm{X}=0$

$\mathrm{b}=$ rata-rata perubahan pada $\mathrm{Y}$ jika $\mathrm{X}$ berubah 1 satuan

$\mathrm{X}_{1}=$ variabel independen pertama (Kepemimpinan)

$\mathrm{X}_{2}=$ variabel independen kedua (Kompetensi)

\section{PEMBAHASAN}

Hasil Uji Reliabilitas

Tabel 3 Uji Reliabilitas

\begin{tabular}{cccc}
\hline Variabel & $\begin{array}{c}\text { Nilai } \\
\text { Alpha }\end{array}$ & $\begin{array}{c}\text { Nof } \\
\text { Item }\end{array}$ & Kesimpulan \\
\hline $\mathrm{X} 1$ & 0,8335 & 9 & Reliabel \\
\hline $\mathrm{X} 2$ & 0,6072 & 6 & Reliabel \\
\hline $\mathrm{Y}$ & 0,6928 & 4 & Reliabel
\end{tabular}

Sumber : Data primer yang diolah, 2019.

Nilai alpha X1 sebesar 0,8335 ini lebih besar dari 0,6 yang artinya instrumen variabel kepemimpinan reliabel. Hal ini berarti responden memberikan jawaban yang konsisten atau seragam. Nilai alpha X2 sebesar 0,6072 nilai ini lebih besar dari 0,6 yang artinya instrumen variabel kompetensi aparat reliabel. Ini artinya responden memberikan jawaban yang konsisten atau seragam. Nilai alpha Y sebesar 0,6928 ini lebih besar dari 0,6 yang artinya instrumen variabel kinerja reliabel. Artinya bahwa responden memberikan jawaban yang konsisten atau seragam.

\section{Hasil Uji Validitas}

Tabel 4

Uji Validitas X1

\begin{tabular}{cccc}
\hline Pernyataan & $\begin{array}{c}\mathrm{r} \\
\text { dengan } \\
\text { total }\end{array}$ & $\begin{array}{c}\text { Niliai } \\
\text { kritis }\end{array}$ & Keterangan \\
\hline 1 & 0,662 & 0,3 & Valid \\
\hline 2 & 0,734 & 0,3 & Valid \\
\hline 3 & 0,835 & 0,3 & Valid \\
\hline 4 & 0,639 & 0,3 & Valid \\
\hline 5 & 0,423 & 0,3 & Valid \\
\hline 6 & 0,544 & 0,3 & Valid \\
\hline 7 & 0,662 & 0,3 & Valid \\
\hline 8 & 0,671 & 0,3 & Valid \\
\hline 9 & 0,759 & 0,3 & Valid \\
\hline
\end{tabular}

Sumber : Data primer yang diolah, 2019.

Berdasarkan hasil uji validitas X1 maka semua butir pertanyaan hasilnya valid yang artinya semua pertanyaan dapat mengukur apa yang hendak diukur yaitu mengukur kepemimpinan.

Tabel 5

Uji Validitas X2

\begin{tabular}{cccc}
\hline Pernyataan & $\begin{array}{c}\mathrm{r} \\
\text { dengan } \\
\text { total }\end{array}$ & $\begin{array}{c}\text { Nilai } \\
\text { kritis }\end{array}$ & Keterangan \\
\hline 1 & 0,374 & 0,3 & Valid \\
\hline 2 & 0,518 & 0,3 & Valid \\
\hline 3 & 0,416 & 0,3 & Valid \\
\hline 4 & 0,450 & 0,3 & Valid \\
\hline 5 & 0,362 & 0,3 & Valid \\
\hline 6 & 0,332 & 0,3 & Valid \\
\hline
\end{tabular}

Sumber : Data primer yang diolah, 2019.

Berdasarkan hasil uji validitas X2 maka semua butir pertanyaan hasilnya valid yang artinya semua pertanyaan dapat mengukur apa yang hendak diukur yaitu mengukur kompetensi aparatur birokrasi. 
Tabel 6

Uji Validitas Y

\begin{tabular}{cccc}
\hline Pernyata & $\begin{array}{c}\mathrm{r} \\
\text { denga } \\
\text { n total }\end{array}$ & $\begin{array}{c}\text { Nilai } \\
\text { kritis }\end{array}$ & Keterangan \\
\hline 1 & 0,727 & 0,3 & Valid \\
\hline 2 & 0,756 & 0,3 & Valid \\
\hline 3 & 0,665 & 0,3 & Valid \\
\hline 4 & 0,736 & 0,3 & Valid \\
\hline
\end{tabular}

Sumber : Data primer yang diolah, 2019.

Berdasarkan hasil uji validitas $\mathrm{Y}$ maka semua butir pertanyaan hasilnya valid yang artinya semua pertanyaan dapat mengukur apa yang hendak diukur yaitu mengukur kinerja aparat.

\section{Hasil Uji Normalitas}

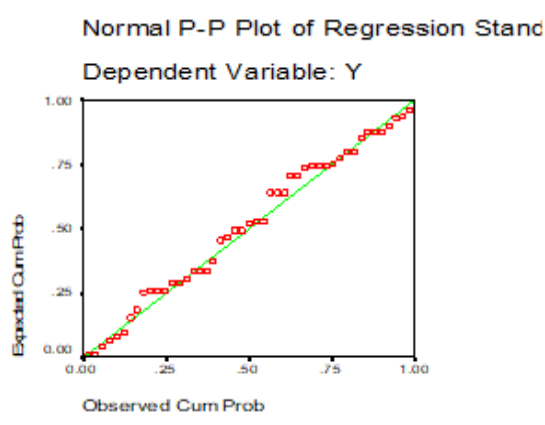

Gambar 3

Grafik Uji Normalitas

Sumber : Data primer yang diolah, 2019

Berdasarkan gambar diatas dapat dilihat bahwa titik-titik data regresi (nilai variabel dependen) menyebar disekitar garis normal (garis diagonal yang menunjukan proyeksi hasil perhitungan variabel dependen). Hal ini menunjukan bahwa data penelitian berasal dari data yang berdistribusi normal
Hasil Uji Korelasi

Tabel 7

Hasil Analisis Korelasi X1 dan X2 terhadap Y

\begin{tabular}{|c|c|c|c|c|}
\hline $\begin{array}{l}\text { Vari } \\
\text { abel }\end{array}$ & $\begin{array}{c}\text { Ketera } \\
\text { ngan }\end{array}$ & $\mathrm{X} 1$ & $\mathrm{X} 2$ & $\mathrm{Y}$ \\
\hline \multirow[t]{3}{*}{$\mathrm{X} 1$} & \multirow{3}{*}{$\begin{array}{l}\text { Pearso } \\
\mathrm{n} \\
\text { Correla } \\
\text { tion } \\
\text { Sig. (2- } \\
\text { tailed) } \\
\mathrm{N}\end{array}$} & 1 & $.789(* *)$ & $.871(* *)$ \\
\hline & & . & .000 & .000 \\
\hline & & 47 & 47 & 47 \\
\hline \multirow[t]{3}{*}{$\mathrm{X} 2$} & \multirow{3}{*}{$\begin{array}{l}\text { Pearso } \\
\mathrm{n} \\
\text { Correla } \\
\text { tion } \\
\text { Sig. (2- } \\
\text { tailed) } \\
\mathrm{N}\end{array}$} & $.789(* *)$ & 1 & $.605(* *)$ \\
\hline & & .000 & . & .000 \\
\hline & & 47 & 47 & 47 \\
\hline \multirow[t]{3}{*}{ Y } & $\begin{array}{l}\text { Pearso } \\
\mathrm{n} \\
\text { Correla } \\
\text { tion }\end{array}$ & $.871(* *)$ & $.605(* *)$ & 1 \\
\hline & $\begin{array}{l}\text { Sig. (2- } \\
\text { tailed) }\end{array}$ & .000 & .000 & \\
\hline & $\mathrm{N}$ & 47 & 47 & 47 \\
\hline
\end{tabular}

Sumber : Data primer yang diolah, 2019.

Berdasarkan tabel di atas maka dapat dijelaskan sebagai berikut:

1. Nilai korelasi X1 dengan $\mathrm{Y}$ sebesar $\mathrm{r}$ $=0,871$, artinya relasi antara kepemimpinan (X1) dengan kinerja (Y) sangat kuat, dan sifat hubungannya + (positif) artinya semakin baik aspek kepemimpinan pada Dinas PUPRPKPP Kota Sukabumi (X1) maka akan semakin baik kinerjanya (Y).

2. Nilai korelasi $X 2$ dengan $Y$ sebesar $r$ $=0,605$ artinya hubungan antara kompetensi aparat (X2) dengan kinerja aparat $(\mathrm{Y})$ adalah kuat, sifat hubungannya + (positif) yang artinya semakin baik kompetensi (X2) maka akan semakin baik pula kinerja aparat Dinas PUPRPKPP Kota Sukabumi (Y).

3. Nilai korelasi $\mathrm{X} 1$ dengan $\mathrm{X} 2$ sebesar $r=0,789$, artinya hubungan antara 
kepemimpinan (X1) dengan kompetensi (X2) adalah kuat.

4. Nilai korelasi dari X1, X2, dengan Y, dapat dilihat dari hasil analisis multi korelasi pada tabel 8 dibawah ini:

Tabel 8

Hasil Analisis Korelasi Ganda X1 dan X2 terhadap Y

\begin{tabular}{ccc}
\hline Model Korelasi & $\mathrm{R}$ & $\mathrm{R}^{2}$ \\
\hline $\mathrm{X} 1-\mathrm{X} 2$ & 0,881 & 0,776 \\
\hline
\end{tabular}

Sumber : Data primer yang diolah, 2019.

Tabel analisis statistik di atas menunjukan relasi kepemimpinan (X1) dan kompetensi (X2) dengan kinerja dilihat dari nilai multiple korelasi yang menunjukan nilai $\mathrm{R}$ $=0,881$, dan besarnya pengaruh dari $\mathrm{X} 1$ dan $\mathrm{X} 2$ terhadap $\mathrm{Y}$ sebesar 77,6 \% $(\mathrm{R}$ square $=$ 0,776 ), pernyataan ini mempunyai arti dampak kepemimpinan (X1) dan kompetensi (X2) terhadap kinerja (Y) memiliki relasi positif dan dampak yang sangat kuat. Sifat relasi positif artinya semakin baik kepemimpinan (X1) dan kompetensi (X2) secara bersama-sama akan meningkatkan kinerja (Y) dengan kontribusi sebesar 77,6\%. Sedangkan sisanya sebesar $22,4 \%$ dipengaruhi oleh faktor lain $(\square)$.

\section{Hasil Uji Regresi}

Berdasarkan analisis regresi diperoleh hasil sebagai berikut :

Tabel 9

Analisis Regresi Variabel Independen Terhadap Variabel Dependen

\begin{tabular}{cccr}
\hline \multirow{2}{*}{ Model } & \multirow{2}{*}{ Variabel } & \multicolumn{2}{c}{$\begin{array}{c}\text { Unstandardized } \\
\text { Coefficients }\end{array}$} \\
\cline { 3 - 4 } & & B & Std. Error \\
\hline 1 & (Constant) & .114 & .402 \\
\hline & $\mathrm{X} 1$ & 1.271 & .142 \\
\hline & $\mathrm{X} 2$ & .309 & .166 \\
\hline
\end{tabular}

Sumber : Data primer yang diolah, 2019.

Berdasarkan tabel analisis regresi tersebut maka diperoleh hasil analisis jalur sebagai berikut:

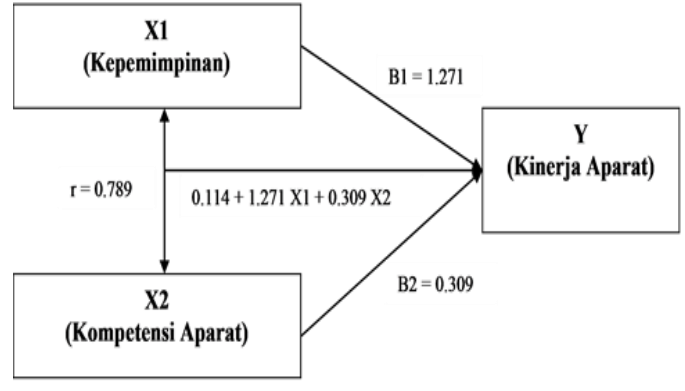

\section{Gambar 4}

Analisis Jalur Antar Variabel

Sumber : Data primer yang diolah, 2019.

Hasil analisis diatas terlihat dalam persamaan regresi berikut ini :

$$
\mathrm{Y}=0,114+1,271 \mathrm{X} 1+0,309 \mathrm{X} 2
$$

Persamaan regresi tersebut mempunyai arti:

a. Nilai konstanta sebesar 0,114 menunjukan bahwa jika tidak ada kenaikan nilai dari variabel kepemimpinan (X1) dan kompetensi aparat (X2) maka nilai kinerja aparat $(\mathrm{Y})$ adalah 0,114 .

b. Nilai koefisien regresi $\mathrm{X} 1$ sebesar 1,271 menunjukan bahwa setiap penambahan/kenaikan satu poin nilai variabel kepemimpinan (X1), maka nilai kinerja aparat (Y) akan naik 1,271 , tetapi dengan asumsi yang lain dianggap tetap, dan signifikan pada $\alpha<0,05$.

c. Nilai koefisien regresi X2 sebesar 0,309 menunjukan bahwa setiap penambahan/kenaikan satu poin nilai variabel kompetensi aparat (X2), maka nilai kinerja aparat (Y) akan naik 0,309 , tetapi dengan asumsi yang lain dianggap tetap, dan signifikan pada $\alpha<0,05$.

d. Persamaaan regresi $\mathrm{Y}=0,114+$ $1,271 \mathrm{X} 1+0,309 \mathrm{X} 2$ menunjukan bahwa jika variabel kepemimpinan (X1) dan kompetensi aparat (X2) secara bersama-sama naik 1 poin, maka kinerja aparat $(\mathrm{Y})$ akan naik sebesar $0,114+1,271+0,309$ dan signifikan pada $\mathrm{F}<0,05$.

Hasil penelitian menunjukkan bahwa aspek kepemimpinan berpengaruh terhadap peningkatan kinerja organisasi secara keseluruhan. Hal ini berimplikasi 
kedepannya bagi organisasi agar terus mempertahankan aspek kepemimpinan yang sesuai dengan tujuan dan kebijakan yang telah digariskan oleh Dinas PUPRPKPP Kota Sukabumi. Temuan penelitian ini mendukung penelitian yang dilakukan oleh (Italiani, 2018; Kurniawan, 2018) yang menyatakan indikator-indikator gaya kepemimpinan semuanya berpengaruh terhadap kinerja pegawai.

Hasil penelitian terhadap kompetensi berdampak positif terhadap kinerja Dinas PUPRPKPP Kota Sukabumi. Implikasinya terhadap organisasi nantinya agar faktor kompetensi aparatur birokrasi tetap dipertahankan atau jika perlu dapat ditingkatkan lagi sesuai dengan arah dan kebijakan yang telah digariskan organisasi. Hasil penelitian ini sesuai dengan yang disimpulkan oleh (Manik \& Syafrina, 2018; Yunus, 2018; Salwa, Away, \& Tabrani, 2018) yang menyatakan dalam penelitiannya bahwa kompetensi berpengaruh positif dan signifikan terhadap kinerja.

Hasil penelitian terhadap aspek kepemimpinan dan kompetensi aparatur birokrasi terhadap peningkatan kinerja pada Dinas PUPRPKPP Kota Sukabumi menunjukkan relasi positif yang kuat artinya bahwa faktor-faktor dari aspek kepemimpinan dan kompetensi aparatur birokrasi harus tetap dipertahankan dan jika perlu ditingkatkan ke arah yang lebih baik lagi sehingga terdapat peningkatan kinerja organisasi dalam melayani masyarakat secara optimal. Temuan ini sejalan dengan penelitian (Lestari, 2019; Putri, 2018; Nasri, Hasmin, \& Firman, 2018; Rahardja, Moeins, \& Lutfiani, 2018) yang menyatakan kepemimpinan dan kompetensi secara simultan memiliki dampak yang signifikan terhadap kinerja.

\section{PENUTUP}

Berdasarkan hasil analisis dan pembahasan penelitian maka dapat ditarik kesimpulan sebagai berikut: Relasi antara kepemimpinan (X1) dengan kinerja (Y) sangat kuat, dan sifat hubungannya positif artinya semakin baik kepemimpinan (X1) maka semakin baik pula kinerja aparatnya (Y). Relasi antara kompetensi (X2) dengan kinerja (Y) kuat, dan sifat hubungannya positif yang artinya semakin baik kompetensi (X2) maka semakin meningkat kinerja (Y). Relasi antara kepemimpinan (X1) dengan kompetensi (X2) adalah kuat. Dampak kepemimpinan (X1) dan kompetensi (X2) terhadap kinerja (Y) memiliki relasi positif yang kuat dan dampaknya juga kuat. Sifat relasinyanya positif, artinya semakin baik kepemimpinan (X1) dan kompetensi (X2) secara simultan akan meningkatkan kinerja secara signifikan $(\mathrm{Y})$.

Saran yang dapat diberikan, seandainya organisasi harus melakukan kebijakan secara parsial untuk meningkatkan kinerja, maka secara keseluruhan harus lebih meningkatkan aspek kepemimpinan dan kompetensi aparatur Dinas PUPRPKPP Kota Sukabumi. Kemudian untuk penelitian selanjutnya, dapat lebih fokus terhadap faktor-faktor yang mempengaruhi kinerja selain kepemimpinan dan kompetensi.

\section{REFERENSI}

Baharun, H. (2016). Manajemen Kinerja Dalam Meningkatkan Competitive Advantage Pada Lembaga Pendidikan Islam. At-Tajdid: Jurnal Ilmu Tarbiyah, 5(2), 243-262.

Bolden, R., Gosling, J., Marturano, A., \& \& Dennison, P. (2003). A review of leadership theory and competency frameworks.

Brudan, A. (2010). Rediscovering performance management: Systems, learning and integration. Measuring Business Excellence, 14(1), 109-123. https://doi.org/10.1108/13683041011 027490

Čižiuniene, K., Vaičiute, K., \& Batarliene, N. (2016). Research on Competencies of Human Resources in Transport Sector: Lithuanian Case Study. Procedia Engineering, 134, 336-343. https://doi.org/10.1016/j.proeng.2016 .01 .016

Day, D. V., Harrison, M. M., \& Halpin, S. M. (2012). An Integrative Theory of Leadership Development: Connecting Adult Development, Identity, and Expertise. New York: Psychology Press.

Dinh, J. E., Lord, R. G., Gardner, W. L., Meuser, J. D., Liden, R. C., \& Hu, J. 
(2013). Leadership theory and research in the new millennium: Current theoretical trends and changing perspectives. The Leadership Quarterly. https://doi.org/10.1016/j.leaqua.2013. 11.005

Italiani, F. A. (2018). Pengaruh Gaya Kepemimpinan Transformasional Dan Transaksional Terhadap Kinerja Pegawai Departemen Sdm Pt. Semen Gresik (Persero) Tbk. BISMA (Bisnis Dan Manajemen), 6(1), 11-18. https://doi.org/http://dx.doi.org/10.26 740/bisma.v6n1.p11-18

Junaidi, R., \& Susanti, F. (2019). Pengaruh Gaya Kepemimpinan Dan Budaya Organisasi Terhadap Kinerja Pegawai Pada UPTD Baltekkomdik Dinas Pendidikan Provinsi Sumatera Barat. Retrieved from https://osf.io/preprints/inarxiv/bzq75/

Katz, R. (1974). Skills of An Effective Administrator. Harvard Business Review, 52(5), 90-102.

Kurniawan, A. W. (2018). Pengaruh Kepemimpinan Dan Pengembangan Sumber Daya Manusia Terhadap Kepuasan Kerja, Motivasi Kerja, Dan Kinerja Karyawan Bank Sulselbar. EKUITAS (Jurnal Ekonomi Dan Keuangan), 16(4), 391-408.

Lertwannawit, A., Serirat, S., \& Pholpantin, S. (2009). Career Competencies And Career Success Of Thai Employees In Tourism And Hospitality Sector. The International Business \& Economics Research Journal, 8(11), 65-72.

Lestari, P. A. (2019). Pengaruh Motivasi, Gaya Kepemimpinan dan Kompetensi Diri terhadap Kinerja Dosen pada Sekolah Tinggi Desain Bali dan Akademi Manajemen Informatika Komputer New Media di Denpasar. JSAM (Jurnal Sains, Akuntansi Dan Manajemen), 1(4), 626-636. https://doi.org/https://doi.org/10.1234 /jsam.v4i1.80

Manik, S., \& Syafrina, N. (2018). Pengaruh Kompetensi Terhadap Kinerja Dosen Sekolah Tinggi Ilmu Ekonomi Riau. Jurnal Ilmiah Ekonomi Dan Bisnis (JIEB), 15(1), https://doi.org/https://doi.org/10.3184 9/jieb.v15i1.72

Nasri, H., Hasmin, \& Firman, A. (2018). Pengaruh Kompetensi, Gaya Kepemimpinan, dan Pelatihan, terhadap Kinerja Aparatur Sipil Negara Sekecamatan Binamu Kabupaten Jeneponto. Jurnal Mirai Management, 3(1), 103-120.

Nugroho, R. E. (2017). Analysis of Talent Management, Employee Engagement and Leadership. International Journal of Economic Perspectives, 11(4).

Osborne, S. P. (2006). The new public governance? Public Management Review, 8(3), 377-387. https://doi.org/10.1080/14719030600 853022

Osei, A. J., \& Ackah, O. (2015). Employee'S Competency and Organizational Performance in the Pharmaceutical Industry. International Journal of Economics, Commerce and Management, III(3), 1-9. Retrieved from https://www.researchgate.net/profile/ Owusu_Ackah/publication/30368981 6_International_Journal_of_Economi cs_Commerce_and_Management_E MPLOYEE'S COMPETENCY AN D_ORGANIZATIONAL_PERFOR MANCE_IN_THE_PHARMACEUT ICAL_INDUSTRY_AN_EMPIRICA L_STUDY_OF_PHARMACEUTIC AL FIRM

Pugh, S. D., \& Dietz, J. (2008). Employee Engagement at the Organizational Level of Analysis. Industrial and Organizational Psychology, 1(1), 4447. https://doi.org/10.1111/j.17549434.2007.00006.x

Putri, P. (2018). Pengaruh Kepemimpinan, Kompetensi dan Budaya Organisasi Terhadap Kinerja Dosen Berbantuan Sofware SPSS. JOURNAL OF SCIENCE AND SOCIAL RESEARCH, 1(1), 86-96.

Rahardja, U., Moeins, A., \& Lutfiani, N. (2018). Leadership, Competency, Working Motivation and Performance of High Private Education Lecturer with Institution Accreditation B: Area Kopertis IV Banten Province. Man 
India, 97(24), 179-192.

Riyanto, A. (2014). Pengaruh Profesionalisme Birokrasi Dan Motivasi Terhadap Kinerja Aparatur Pemerintah Pada Dinas Pendapatan, Pengelolaan Keuangan Dan Aset Daerah Kota Sukabumi. In Seminar Nasional Inovasi dan Tren (SNIT) (p. B-33-B-41). Retrieved from https://www.researchgate.net/profile/ Andi_Riyanto2/publication/2929605 79_PENGARUH_PROFESIONALIS ME_BIROKRASI_DAN_MOTIVAS I_TERHADAP_KINERJA_APARA TUR_PEMERINTAH_PADA_DINA S_PENDAPATAN_PENGELOLAA N_KEUANGAN_DAN_ASET_DAE RAH_KOTA_SUKABUMI/links/56 b211cd08aed7ba3f

Salwa, A., Away, Y., \& Tabrani, M. (2018). Pengaruh Komitmen, Integritas Dan Kompetensi Terhadap Kinerja Pegawai Serta Dampaknya Pada Kinerja Komisi Independen Pemilihan (KIP) Aceh. Jurnal Magister Manajemen, 2(1), 58-67.

Schermerhorn, J. R. (1996). Managament. John Wiley \& Sons (Asia) Pte. Ltd.

Timpe, A. D. (2002). Manajemen Sumber Daya Manusia Kinerja. Jakarta: Gramedia.

Uhl-bien, M. (2006). Relational Leadership Theory: Exploring the social processes of leadership and organizing, 17, 654-676. https://doi.org/10.1016/j.leaqua.2006. 10.007

Walker, R. M., Boyne, G. A., \& Brewer, G. A. (2010). Public Management and Performance: Research Directions. Cambridge University Press.

Weber, M. R., Finley, D. A., Crawford, A., \& Rivera, D. (2009). An Exploratory Study Identifying Soft Skill Competencies in Entry-Level Managers. Tourism and Hospitality Research, 9(4), 353-361. https://doi.org/10.1057/thr.2009.22

Yunus, E. (2018). Pengaruh Kompetensi Sumber Daya Manusia Terhadap Kinerja Pegawai KPPBC Tipe Madya Pabean Tanjung Perak Surabaya. EKUITAS (Jurnal Ekonomi Dan Keuangan), 16(3), 368-387.
Yup Chung, K. (2000). Hotel management curriculum reform based on required competencies of hotel employees and career success in the hotel industry. Tourism Management, 21(5), 473487. https://doi.org/10.1016/S02615177(99)00102-8

\section{BIODATA PENULIS}

Andi Riyanto, merupakan salah satu dosen di Universitas Bina Sarana Informatika pada Program Studi Sistem Informasi Akuntansi Kampus Kota Sukabumi. Saat ini aktif mengajar pada mata kuliah Akuntansi Dasar, Pemeriksaan Akuntansi dan Metode Penelitian. Tertarik pada riset bidang Sistem Informasi, Akuntansi, Manajemen dan Ilmu Sosial 